Research

\title{
Model for estimating the population prevalence of chronic obstructive pulmonary disease: cross sectional data from the Health Survey for England
} Luis C Nacul ${ }^{* 1}$, Michael Soljak² and Tom Meade ${ }^{3}$

\begin{abstract}
Address: ${ }^{1}$ Health Protection Agency, 7th Floor Holborn Gate, 330 High Holborn, WC1V 7PP London, UK, 2 Public Health Information \& Intelligence Strategy, Health Improvement Directorate, Department of Health, Skipton House, 80 London Road, SE1 6LH London, UK and ${ }^{3}$ Department of Epidemiology and Population Health, London School of Hygiene and Tropical Medicine, Keppel Street, WC1E 7HT London, UK

Email: Luis C Nacul* - Luis.nacul@hpa.org.uk; Michael Soljak - Michael.soljak@dh.gsi.gov.uk; Tom Meade - Tom.Meade@lshtm.ac.uk

* Corresponding author
\end{abstract}

Published: 26 September 2007

Population Health Metrics 2007, 5:8 doi:10.1 186/1478-7954-5-8

This article is available from: http://www.pophealthmetrics.com/content/5/l/8

(c) 2007 Nacul et al; licensee BioMed Central Ltd.

This is an Open Access article distributed under the terms of the Creative Commons Attribution License (http://creativecommons.org/licenses/by/2.0), which permits unrestricted use, distribution, and reproduction in any medium, provided the original work is properly cited.
Received: 13 March 2007

Accepted: 26 September 2007

\begin{abstract}
Background: Chronic obstructive pulmonary disease (COPD) is a major but neglected public health problem. Currently I.4\% of the England population has a clinical diagnosis of COPD, but the true burden of the disease has not been known with certainty, as many cases remain undiagnosed.

Methods: A mathematical model based on cross sectional data from a representative sample of the population in England (the Heath Survey for England 200I, $n=10,750$ ) was developed allowing estimates on the prevalence of COPD (defined based on the presence of airflow obstruction) to be obtained. Logistic regression analysis was used to investigate and choose risk factors for inclusion in the model and to derive the prevalence estimates based on the strength of association between selected risk factors and the outcome COPD. The model allows the prevalence to be estimated in populations at national level and also at regional and large local areas, based on their compositions according to age, sex, smoking and ethnicity, and on area degrees of urbanisation and deprivation. We applied the model to measure the prevalence of COPD in England and in some sub-groups of the population within the country.
\end{abstract}

Results: The prevalence of COPD in England is estimated as $3.1 \%$ (3.9\% in men and $2.4 \%$ in women) in the population over 15 years of age, and 5.3\% (6.8\% in men and $3.9 \%$ in women) in 45 year-olds and over. There was a 7-fold variation in the prevalence across subgroups of the population, with lowest values in Asian women from wealthy rural areas (1.7\%), and highest in black men from deprived urban areas (12.5\%).

Conclusion: The model can be used to estimate population prevalence of COPD from large general practices to national level, and as a tool to identify areas of high levels of unmet needs for COPD priority health actions. The results from the model highlight the importance of including variables other than age, sex and smoking, i.e. levels of deprivation, urbanisation and ethnicity, when estimating population prevalence of COPD. The model should be validated at local level and incorporated into case-finding strategies. 


\section{Background}

Chronic obstructive pulmonary disease (COPD) is a chronic condition characterised by progressive airflow obstruction, which is not completely reversible. COPD accounts for nearly 30,000 deaths each year in the United Kingdom (UK), corresponding to 5.7 percent of adult male and 4 percent of adult female deaths, including a significant number of premature deaths. In addition, 1.4\% of the population consult their general practitioners (GPs) for COPD each year. It accounts for $2 \%$ of hospital admission spells and over 3 percent of bed-days in adults [1], costing the NHS $£ 800$ million, and leading to 24 million working days lost each year [2].

As expected, the prevalence of COPD is higher in smokers and in men, and it increases with age. Other risk factors of public health importance include air pollution [3], socioeconomic deprivation [3], occupational exposures [3,4] and possibly ethnicity [5-7]. There is considerable variation in the reported prevalence of COPD.

Models using smoking rates to estimate COPD prevalence have been previously proposed [8-10], but none has direct relevance to the UK. We therefore developed a model (Model-HSE) to estimate the prevalence of COPD based on existing data from the Health Survey for England (HSE) 2001 [11], which has nevertheless not been used for this purpose before. It uses the main risk factors for COPD reported in the literature, particularly those that are easily measured and for which information is readily available. This report explains how the model was developed, and uses the population of England to illustrate its application.

\section{Methods}

\section{Data sources}

The distribution of COPD in the population of England was based on the HSE 2001 findings for lung function parameters and their association with relevant risk factors. The methods used in the HSE 2001 are described in detail elsewhere [11]. In brief, the survey included a representative sample of the population who had their lung function evaluated using a portable spirometer with a calibration device (Vitalograph 'Escort Spirometer'). Comprehensive data on risk factors were also collected as part of the survey. The data refer to 5,269 men and 6,133 women over 15 years old with valid lung function measures. This corresponds to $98 \%$ of men and $95 \%$ of women visited by a research nurse as part of the survey. For $99.3 \%$ of these, data were available for all of age-group, smoking status, ethnicity and degree of urbanisation. Data were available for deprivation score and all of the above risk factors in $94.3 \%$ of the final sample, which was used for the multivariate analysis. This included 4,970 men and 5779 women.
COPD was defined according to British Thoracic Society (BTS) criteria [12], based on the values of forced expiratory volume in 1 second $\left(\mathrm{FEV}_{1}\right)$ and the forced vital capacity (FVC) i.e. $\mathrm{FEV}_{1} / \mathrm{FVC}<0.70$ and $\mathrm{FEV}_{1}<80 \%$ predicted using British reference values derived from the HSE [13].

\section{Model construction}

The choice of variables for inclusion in the model was based on logistic regression analysis that examined predictors of COPD using the HSE 2001 dataset. Explanatory variables obtained from the HSE dataset and included in the final model were (categories of each variable shown in brackets): gender, age group (15-34 year olds, 10 year age groups from 35 up to 74 years of age and 75 year olds and over), smoking status (smoker, former smoker, never smoker), ethnicity (White, Black or Black British, and Asian or Asian British), area of residence (rural, urban and suburban) and area based index of deprivation (quintile of deprivation score based on Index of Multiple Deprivation[14]).

The baseline odds of COPD (in non-smokers under 35 years old) were obtained directly from the data. Separate baseline odds were estimated for each gender, and also according to ethnicity, area of residence and area-based deprivation score.

The logistic model was used to derive the odds ratios and prevalence ratios for COPD for subjects with various combinations of risk factors in relation to baseline. The prevalence in each age group, gender, ethnic group, area of residence and level of deprivation, and smoking status category were derived from the odds, using the formula: Prevalence $=$ odds $/(1+$ odds $)$.

\section{Model application}

The input variables, which could be defined by the relevant user, e.g. at Primary Care Trust, include age-group, gender, smoking prevalence by gender and age, area of residence, area based deprivation score and ethnic distribution of the population.

\section{Model outputs}

The main model outputs are the prevalence of COPD by gender for the relevant geographic area, at national, regional or local level, as defined by the user. To illustrate the use of the model, we have used here population inputs for England, based on the mid-2005 estimated population distribution [15] and the national smoking prevalence by age-group and gender for 2004-2005 [16].

\section{Model assumptions}

The model assumptions include: i) The real prevalence of COPD in non-smokers under 35 years of age (baseline prevalence) is the same as the prevalence in non-smokers 
of the same age group and gender in the 2001 HSE population; ii) The ratio of odds and prevalence of COPD in the various age groups compared to the baseline group is the same as in the HSE for each gender, smoking status and other risk factors in the model; iii) the risks in those falling within each of the risk categories are uniform.

We also obtained the prevalence of COPD considering alternative scenarios, which assume that: a) the prevalence of COPD in under $35 \mathrm{~s}$ or under $40 \mathrm{~s}$ is uniform across smoking status in each gender, and is equal to the average baseline prevalence found at the HSE (therefore it does not consider any increase in risk due to smoking in this age group); or b) the prevalence of COPD is zero in under $35 \mathrm{~s}$ or in under $40 \mathrm{~s}$; or c) ethnicity does not have an effect on the risk of COPD, and the risks in white populations apply to all ethnic groups.

\section{Results \\ Risk factors for COPD and selection of variables for Model-HSE}

Table 1 shows the results of the univariate and final regression logistic models assessing risk factors for COPD. Risk of COPD is significantly lower in women than in men (odds ratio $(\mathrm{OR})=0.64 ; 95 \% \mathrm{CI}=0.54-0.76 ; \mathrm{p}<0.001$ ). As gender was shown to modify the effect of other variables on the outcome, the analyses were carried out separately for men and women. No other significant interactions were found in the data, including between age-group and smoking status.

The final model shows age group and smoking history are the strongest predictors of COPD in both genders. Residence in urban areas and possibly black ethnicity are also associated with increased risk, particularly in women. Living in more deprived areas is associated with increased risk in men, but not in women. Being Asian appears to be protective in women, although this association did not reach statistical significance.

\section{Application of HSE-model to England population}

Table 2 and Figure 1 show the prevalence of COPD by age and gender in England. The overall prevalence in the population over 15 years of age was 3.1\% (3.9\% in men and $2.4 \%$ in women). For those over 45 years old, the estimated prevalence was $5.3 \%(6.8 \%$ and $3.9 \%$ in men and women respectively). This corresponds to over 1.3 million people in England with COPD, of whom nearly 800 thousand or $60 \%$ are men.

The assumption that ethnicity is not associated with being a case of COPD, i.e. that all population has the same risk of whites, did not change the total national prevalence estimates considerably $(1,297$ thousand in 15 year-olds and over and 1,065 thousand over 45 s under this assump- tion). When we considered the risk of COPD in under $35 \mathrm{~s}$ as equal to the average baseline risk in this age group (in non-smokers), the total number of cases estimated was reduced by 60,800 , resulting in an overall prevalence of 1.25 million or $3 \%$ (3.8\% in men and $2.3 \%$ in women). Considering the risk in all over 40 s as equal to the average baseline risk, the total number of cases is reduced further to $1, .223,200$ (3.0\% overall prevalence; $3.7 \%$ in men and $2.3 \%$ in women). If we consider the risk in under $35 \mathrm{~s}$ as inexistent, the total number of estimated cases decreases to $1,185,700$ (2.9\% overall prevalence; $3.4 \%$ in men and $2.2 \%$ in women). Assuming the more extreme situation of zero risk in all under $40 \mathrm{~s}$, the prevalence comes down to $1,128,550(2.7 \%$ overall; or $3.4 \%$ in men and $2.11 \%$ in women), representing a decrease of 174,500 compared to the original estimates The latter estimates assume that all cases of airflow obstruction in the younger age groups are due to other diagnoses than COPD, such as asthma.

Table 3 shows the estimated prevalences of COPD in urban, suburban and rural England, based on the national population distribution and smoking prevalence. The values in brackets show the estimated average prevalence for areas in the lower and highest quintiles of deprivation. The average prevalence in over $45 \mathrm{~s}$ varies 4 -fold, with the highest values in men in deprived urban areas, and the lowest in women in wealthy rural areas. When the effect of ethnicity is also considered, the variation in prevalence reaches 7 -fold, from $1.7 \%$ in Asian women from rural areas in the lower quintile of deprivation to $12.5 \%$ in black men from urban areas in the upper quintile of deprivation.

\section{Discussion}

We developed a mathematical model that enables the prevalence of COPD to be estimated based on information that is easily available to Primary Care Trusts and many individual general practices. The model takes into account the increasing prevalence of COPD with age and smoking, and the modifying effect of gender. It also considers a higher risk of COPD among those living in urban environments and in areas of higher deprivation, and in black ethnicities.

As expected, the risk associated with smoking and formersmoking is higher in men compared to women. This may be related to their longer history and intensity of smoking, as compared to women. The effects of ethnicity and area of residence are more evident in women, among whom deprivation score is not apparently relevant, after other variables are considered. Urban environment increases the risk of COPD, possibly through higher air pollution levels. Social deprivation may increase the risk of COPD through complex mechanisms in addition to the higher prevalence of smoking. This may include different smok- 
Table I: Risk factors for COPD included in the final prevalence model

\begin{tabular}{|c|c|c|}
\hline Variable & Odds Ratio $(95 \% \mathrm{Cl})$ (univariate model) & Odds Ratio (95\% Cl) (final logistic model) \\
\hline \multicolumn{3}{|c|}{ MEN $(n=4970)$} \\
\hline Smoking Status & $(P<0.00 \mathrm{I})$ & $(P<0.001)$ \\
\hline - Never smoker & 1 & 1 \\
\hline - Former smoker & $3.63(2.54-5.21)$ & $2.18(1.48-3.23)$ \\
\hline - Current Smoker & $3.81(2.64-5.52)$ & $4.50(3.01-6.74)$ \\
\hline Age-group (in years of age) & $(P<0.00 \mathrm{I})$ & $(P<0.00 \mathrm{I})$ \\
\hline$-<35$ & 1 & 1 \\
\hline$-35-44$ & $1.65(0.86-3.17)$ & $1.94(0.99-3.78)$ \\
\hline$-45-54$ & $2.45(1.33-4.50)$ & $2.66(1.41-4.99)$ \\
\hline$-55-64$ & $6.91(4.02-11.89)$ & $7.92(4.46-14.07)$ \\
\hline$-65-74$ & $10.40(6.08-17.80)$ & $12.69(7.12-22.60)$ \\
\hline$-75+$ & $12.15(6.78-21.76)$ & $16.02(8.57-29.94)$ \\
\hline Area of residence & $(P=0.02)$ & $(P=0.25)$ \\
\hline - Urban & 1 & 1 \\
\hline - Suburban & $0.70(0.50-0.97)$ & $0.74(0.51-1.06)$ \\
\hline - Rural & $0.58(0.39-0.86)$ & $0.72(0.46-1.15)$ \\
\hline Ethnicity & $(P=0.64)$ & $(P=0.95)$ \\
\hline - White & I & I \\
\hline - Black/Black British & $1.20(0.48-2.99)$ & $1.17(0.44-3.10)$ \\
\hline - Asian/Asian British & $0.69(0.28-1.70)$ & $0.97(0.37-2.5 I)$ \\
\hline Quintile of Multiple Deprivation Score & $1.22(1.11-1.34)(P<0.001)$ & $1.17(1.05-1.31)(P=0.005)$ \\
\hline \multicolumn{3}{|c|}{ WOMEN (n = 5779) } \\
\hline Smoking Status & $(P<0.00 I)$ & $(P<0.001)$ \\
\hline - Never smoker & I & I \\
\hline - Former smoker & $1.70(1.07-2.64)$ & $1.26(0.79-2.0 \mathrm{I})$ \\
\hline - Current Smoker & $3.53(2.43-5.14)$ & $4.11(2.74-6.15)$ \\
\hline Age-group (in years of age) & $(P<0.00 \mathrm{I})$ & $(P<0.00 \mathrm{I})$ \\
\hline$-<35$ & 1 & I \\
\hline$-35-44$ & $1.08(0.53-2.19)$ & I.35 (0.65-2.79) \\
\hline$-45-54$ & $2.34(1.28-4.30)$ & $2.69(1.42-5.09)$ \\
\hline$-55-64$ & $4.18(2.34-7.47)$ & $6.03(3.26-11.15)$ \\
\hline$-65-74$ & $5.36(2.99-9.61)$ & $8.04(4.33-14.91)$ \\
\hline$-75+$ & $5.34(2.79-10.22)$ & $10.40(5.18-20.87)$ \\
\hline Area of residence & $(P=0.01)$ & $(P=0.04)$ \\
\hline - Urban & I & I \\
\hline - Suburban & $0.62(0.42-0.92)$ & $0.59(0.39-0.90)$ \\
\hline - Rural & $0.47(0.29-0.77)$ & $0.55(0.32-0.96)$ \\
\hline Ethnicity & $(P=0.19)$ & $(P=0.50)$ \\
\hline - White & I & I \\
\hline - Black/Black British & $1.14(0.42-3.12)$ & I.8I $(0.64-5.14)$ \\
\hline - Asian/Asian British & $0.24(0.03-1.76)$ & $0.60(0.08-4.47)$ \\
\hline Quintile of Multiple Deprivation Score & $1.18(1.05-1.34)(P=0.005)$ & $1.11(0.98-1.27)(P=0.11)$ \\
\hline
\end{tabular}




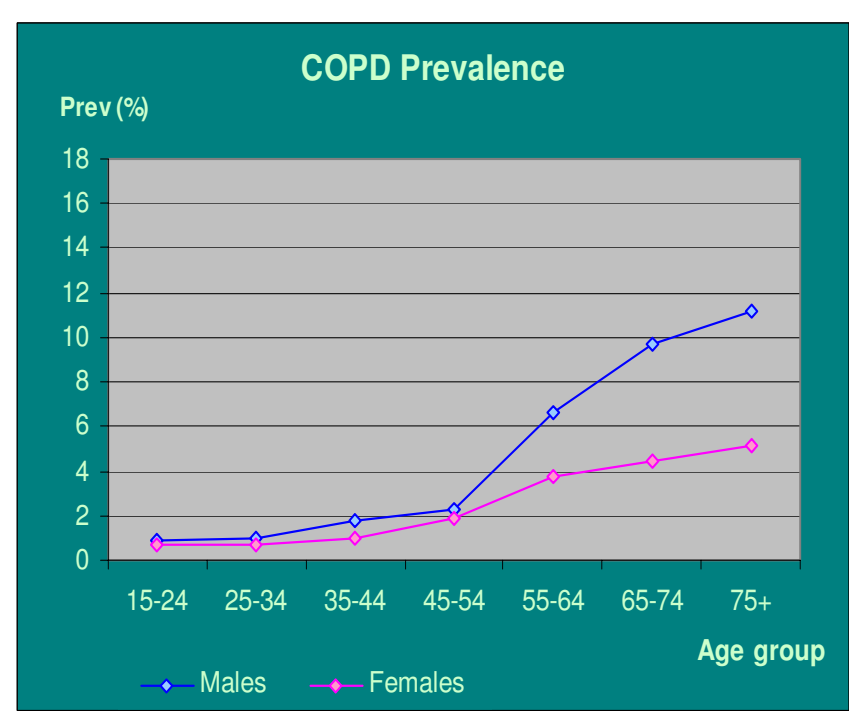

Figure I

Estimated real prevalence of COPD in England population of median deprivation score by age-group and gender.

ing habits (the model does not take into account duration and intensity of smoking as such information is not readily available), and a higher likelihood of exposure to other risk factors, which are not easily measured, such as passive exposure to tobacco smoking, history of respiratory infections, and less access to health services and information. Ethnic differences in susceptibility are less clear and less well understood, but might involve a combination of behavioural, environmental and possibly genetic factors.

We estimated the overall prevalence of COPD in England as $3.1 \%$ in people over 15 years old and $5.3 \%$ in those over 45 years old. The model illustrates the huge inequalities in the prevalence of COPD across England, with extreme risks in black men in urban deprived areas in one end of the risk spectrum, and Asian women in the lowest deprived rural areas, in the opposite end, between whom the risk of COPD varies 7 -fold on average. Thus simpler models that do not take into account such variations in prevalence across population groups, or the extrapolation of national COPD prevalence figures for smaller areas, would be inappropriate for local use.

A systematic review of good quality COPD prevalence studies yielded estimates for England of between 4\% and $10 \%$ [17]. The Health Needs Assessment report suggests a prevalence of 5\% for men and 3\% for women of middle age and upwards [18]. Our results are similar to the latter, but not as high as suggested by some of the studies used for the former review. The decreasing trend in smoking prevalence in England is likely to lead to slow reductions in the real prevalence of COPD. However, major causes of variations in estimates include differences in the populations and in the diagnostic criteria used [19]. This is illustrated by the finding of a prevalence of $13.3 \%$ in over $35 \mathrm{~s}$ in the HSE survey, when a different definition of COPD was used [20]. That study also calculated the prevalence directly from the survey data, differently from our study, where estimates were extrapolated for the population of England.

The figures estimated by the Model-HSE for England are in general slightly lower than, but comparable with other studies on COPD using the same BTS definition, i.e. $4.5 \%$ in Norway [21], 6.8\% in the US [22] and 6.8\% in white males 40-60 years old in Spain [23]. They are also similar to the overall prevalence of $6.1 \%$ found in the NICECOPD study for Belfast white population aged 40 to 69 years [24]. The slightly lower estimated prevalence in our study may be largely explained by the lower smoking prevalence in England, but also by differences in the study populations, and the larger study size of the Health Survey for England.

Comparisons of our results with studies that used other definitions of COPD are difficult to interpret. Estimates based on self-reported symptoms tend to overestimate the prevalence. This is because diagnostic specificity is reduced as other respiratory diseases may be misdiagnosed as COPD, although asymptomatic cases of airflow obstruction will be missed. On the other hand, medically

Table 2: Number and proportion of people estimated to have COPD by age group and gender in England (estimates for 2005)

\begin{tabular}{lccc}
\hline Age-group (Years) & Men Number (\%) & Women Number (\%) & Both sexes Number (\%) \\
\hline $15-44$ & $137,530(1.30)$ & $93,450(0.89)$ & $230,980(1.10)$ \\
$45-54$ & $75,720(2.38)$ & $64,840(2.00)$ & $140,560(2.19)$ \\
$55-64$ & $198,400(6.90)$ & $122,440(4.11)$ & $320,840(5.48)$ \\
$65-74$ & $199,840(10.03)$ & $105,740(4.81)$ & $305,580(7.29)$ \\
$75+$ & $172,700(11.65)$ & $132,400(5.55)$ & $305,100(7.89)$ \\
\hline Total 15+ & $784,190(3.89)$ & $518,870(2.41)$ & $1,303,060(3.15)$ \\
Total 45+ & $646,660(6.76)$ & $425,420(3.92)$ & $1,072,080(5.27)$ \\
\hline
\end{tabular}

\footnotetext{
* Values in brackets indicate age-gender specific prevalence rates (\%) of COPD
} 
Table 3: Estimated prevalence P (percent) of COPD in England and according to area of residence

\begin{tabular}{lllll}
\hline Area & P men age I5+ & P men age 45+ & P women I5+ & P women 45+ \\
\hline Urban & $4.86(3.65-6.47)$ & $8.41(6.35-11.12)$ & $3.68(2.91-4.39)$ & $5.95(4.71-7.05)$ \\
Suburban & $3.74(2.75-4.94)$ & $6.50(4.79-8.55)$ & $2.23(1.79-2.69)$ & $3.62(2.91-4.36)$ \\
Rural & $3.65(2.75-4.85)$ & $6.35(4.80-8.40)$ & $2.05(1.67-2.53)$ & $3.33(2.72-4.10)$ \\
\hline England & $\mathbf{3 . 8 9}(\mathbf{2 . 8 9 - 5 . 1 6 )}$ & $\mathbf{6 . 7 6 ( 5 . 0 4 - 8 . 9 2 )}$ & $\mathbf{2 . 4 I}(\mathbf{I . 9 4 - 2 . 9 2 )}$ & $\mathbf{3 . 9 2 ( 3 . 1 5 - 4 . 7 2 )}$ \\
\hline
\end{tabular}

* Values in brackets correspond to mean values in extreme quintiles of deprivation score, or approximately the $10^{\text {th }}$ and $90^{\text {th }}$ percentiles of the prevalence distribution.

diagnosed COPD tends to under-estimate the true prevalence of the disease, as diagnostic sensitivity is reduced. Compared to other commonly used COPD spirometricbased case definitions, the BTS is based on quite conservative cut-off points, yielding relatively low estimate values $[10,17]$.

A main advantage of the Model-HSE is that it is based on high quality data from a large representative sample of the population, and uses standard and specific diagnostic criteria for COPD, which is based on lung function rather than symptoms. Response rates were high in the survey with the achieved samples matching the target populations closely [25]. Prevalence estimates are based on the strength of association between key risk factors for COPD, including the effects of ethnicity, area of residence and deprivation, which were shown to be independent risk factors for COPD in the HSE survey. This represents a significant advantage in relation to previous COPD prevalence models $[8,9]$, which were based only on smoking status, age and gender (also used in the Model-HSE) of mostly white populations outside the United Kingdom. The input data are usually readily available at local level.

The model uses current smoking status (never, former, current) as surrogates for total exposure to cigarette smoke, and is therefore not ideal to predict short term effects of changes in smoking prevalence (e.g. following intervention), due to long latent periods, large time lag between intervention and effects, and irreversibility of disease. However, the model is not static and will be updated over time, as parameters' values change, e.g. smoking prevalence (in England there are regular estimates of smoking prevalence at sub-regional level). Noteworthy, since intensity and duration of smoking (and thus smoking associated risk of COPD) tend to be lower in younger populations [25], the model may slightly overestimate the prevalence in young people. Another reason for prevalence overestimation in young ages is a possible misclassification of cases of asthma into COPD (note reversibility test was not used in the HSE). We dealt with these by providing alternative estimates for the prevalence of COPD, applying baseline or nil prevalence rates in all those under 35 and under 40 years old. These brought the overall prev- alence estimates down by $0.1 \%$ to $0.4 \%$. The model also relies on the quality of smoking and other data, and does not take into account competing causes of morbidity and mortality in the population, e.g. cardiovascular disease and lung cancer, which may affect prevalence of COPD. Moreover, it still needs correction for populations with significant occupational exposures. There is some degree of imprecision in the estimates, which are larger when the rates are estimated for smaller populations or sub-groups, such as ethnic minorities and specific age-groups. Therefore we recommend that it is used primarily to derive overall population prevalence estimates, rather than estimates within population sub-groups. Further validation with a representative sample of the UK population including large proportions of people from ethnic minorities is still needed, before it may be reliably used in small population groups, such as GP practices and in ethnic minorities. We are currently planning to validate the model at practice level in North West London and investigating the feasibility of two COPD case-finding strategies.

Respiratory function indices have been shown to be predictive of mortality from respiratory disease, cardiovascular disease and all cause mortality [26,27]. Airflow limitation may precede the development of significant symptoms of COPD by many years and its progression is directly linked to the continuing exposure to risk factors, particularly tobacco smoking. As COPD is difficult to diagnose clinically (without spirometry) in its milder forms, it is often diagnosed late - the average age at diagnosis of COPD in the UK is 67 years [28].

Widespread use of spirometry allowing early detection of airflow obstruction has been increasingly advocated as it enables early management of COPD [29]. Stopping smoking prevents the development of COPD, or slows its progress and reduces the risk of hospital admissions [30]. Smoking cessation programmes are highly cost-effective, and crucially, have been specifically shown to be costeffective when directed to individuals with asymptomatic airway obstruction [31]. This is because smokers may be motivated to attempt to quit when given a diagnosis of airflow limitation [32]. The incremental cost effectiveness ratio (ICER) of opportunistic COPD case-finding for this 
purpose is a cost per life year gained of $£ 713.16$ and a cost per QALY of $£ 814.564$ [1].

The magnitude of undiagnosed cases can be ascertained by comparing the model estimates with the recorded prevalence of COPD, to indicate the extent of unmet needs in COPD. In the UK this is facilitated by GP performance payments for COPD management through the Quality and Outcomes Framework (QOF) of the GP Contract based on an electronic register of all patients with diagnosed COPD. If this is linked to case finding and intervention, there is a potential for reducing the population burden and progression of the disease.

The average QOF-diagnosed prevalence of COPD in England reported in 2004-5 through the Quality and Outcomes Framework of the GP Contract was only $1.4 \%$ [33]. This indicates that around 600,000 or nearly half of the 1.3 million COPD cases remain undiagnosed. A relatively large number of these individuals live in London or North of England (data not shown). Many of such cases will continue their risk behaviours and eventually present to the health services at later stages as more severe cases, possibly through emergency hospital admissions. Many of them will become high intensity users of health services, with considerable costs to individuals, the NHS and society. An audit of 80,000 COPD admissions showed that $70 \%$ of them are of patients not previously admitted with the condition (Bird $\mathrm{M}$, personal communication).

The Model-HSE may be freely obtained directly from the authors and is publicly available on the Eastern Region Health Observatory website [34]. It may be used, with the qualifications stated above, by general practices and primary care trusts (PCTs), in England, and indeed in other user defined populations in the country and probably in other countries of the UK i.e. Wales, Scotland and Northern Ireland. General practices can use their own data on the population distribution by age-group and gender, smoking prevalence, ethnicity, degree of urbanisation and deprivation score for the area where the practice is located, to obtain indicative figures on the prevalence of COPD in their population. Data from the Primary Care Trust where the practice is located may be used as a proxy (with any relevant adjustments) in cases where practice specific data are not available. In addition it may be valid in Western populations that are not too dissimilar from England.

\section{Conclusion}

We believe that compared to previous models and prevalence estimates, the HSE-Model offers the most reliable estimates for England and the United Kingdom. It recognises deprivation, urban living and ethnicity as independent risk factors for COPD, which are taken into account in the estimates derived, in addition to smoking, age and gender. The model gives prevalence estimates for areas of varying sizes, including large populations at local level, however, the precision of the estimates will be higher for larger areas.

The overall prevalence of COPD in England is estimated as 1.3 million, of whom as many as 600,000 people may be unaware of their diagnosis, therefore missing the opportunity of benefiting from early interventions. This emphasises the importance of active case finding and the model can be used to identify areas with a high level of unmet needs, i.e. with a high proportion of undiagnosed disease, where the benefits of case finding would be optimised. This strategy may also have an impact on reducing health inequalities, due to the socio-economic class gradient in COPD prevalence. The model should be validated, and case-finding strategies using the model should be evaluated for their cost-effectiveness.

\section{Competing interests}

The author(s) declare that they have no competing interests.

\section{Authors' contributions}

$\mathrm{LN}$ was responsible for the conception and design, analysis and interpretation of data, and drafted the article. MJ contributed to conception, design and interpretation of data and with critical revision for important intellectual content. TM contributed to analysis and interpretation of data and revisited it critically for important intellectual content. All authors read and approved the final manuscript.

\section{Acknowledgements}

We are grateful to the Health Survey for England for allowing us access to the 200 I dataset for this study. We would also like to thank the various people at the former North West London Strategic Health Authority, London School of Hygiene and Tropical Medicine, Imperial College and Harrow Primary Care Trust who helped us in many different ways. There are too many to mention, but you know who you are. We really appreciated. We especially thank Dr Azeem Majeed for the useful suggestions and for revising an earlier draft. We received no specific funding for this project.

\section{References}

I. National collaborating centre for chronic conditions: Chronic Obstructive Pulmonary Disease. National clinical guideline on management of chronic obstructive pulmonary disease in adults in primary and secondary care. Thorax 2004, 59(Suppl I): I-232.

2. Department of Health: Annual Report of the Chief Medical Officer 2004 on the state of public health. London ; 2005.

3. Hansell AL: The epidemiology of chronic obstructive pulmonary disease in the UK: spatial and temporal variations. In PhD Thesis Faculty of Medicine of the University of London, Imperial College, St Mary's Campus; 2004.

4. Rushton L: Review of the literature on chronic bronchitis and emphysema and occupational exposure Leicester, UK: Institute of Environmental Health; 2004.

5. Barnes PJ: Molecular genetics of chronic obstructive pulmonary disease. Thorax 1999, 54:245-52. 
6. Chatila WM, Wynkoop WA, Vance G, Criner G]: Smoking patterns in African Americans and Whites with advanced COPD. Chest 2004, I 25: 15-2I.

7. Enright PL, Kronmal RA, Higgins M, Schenker M, Haponik EF: Spirometry reference values for women and men 65 to 85 years of age. Am Rev Respir Dis 1993, 147:125-133.

8. Talitha L, Feenstra TL, van Genugten MLL, Hoogenveen RT, Wouters $\mathrm{EF}$, van Molken MPMHR: The impact of aging and smoking on the future burden of chronic obstructive pulmonary disease. Am J Respir Crit Care Med 200I, 164:590-96.

9. Stang P, Lydic E, Silberman C, Kempel A, Keating ET: The prevalence of COPD: using smoking rates to estimate disease frequency in the general population. Chest 2000, II7(5 Suppl 2):354S-359S.

10. Lopez AD, Shibuya K, Rao C, Mathers CD, Hansell AL, Held LS, Schmid V, Buist S: Chronic obstructive pulmonary disease: current burden and future projections. Eur Respir J 2006, 27(2):397-4I2.

II. Primatesta P, Stamatakis E: Health Survey for England 200I: Respiratory symptoms, atopic conditions and lung function London: The Stationery Office; 2003

12. BTS guidelines for the management of chronic obstructive pulmonary disease. The COPD guidelines group of the standards of care committee of the BTS. Thorax 1997, 52(Suppl 5):SI-S28.

13. Falaschetti E, Laiho J, Primatesta P, Purdon S: Reference equations for normal and low lung function from the Health Survey for England. Eur Respir J 2004, 23:456-63.

14. Office for the Deputy Prime Minister: The English Indices of Deprivation 2004 (revised). London 2004.

15. Office for National Statistics [http://www.statistics.gov.uk/]

16. Goddard E: General house survey 2005. Smoking and drinking among adults, 2005 London: Office for National Statistics; 2006.

17. Halbert RJ, Isonaka S, George D, labal A: Interpreting COPD prevalence estimates. What is the true burden of disease? Chest 2003, I 23(5): 1684-92.

18. Walters S, Ward W: Lower respiratory disease. In Health Care Needs Assessment. First Series Volume I. 2nd edition. Edited by: Stevens A, Raftery J, Mant J. Abingdon, UK: Radcliffe; 2004:245-92.

19. Viegi G, Pedreschi M, Pistelli F, Di Pede F, Baldacci S, Carrozzi L, Giuntini $C$ : Prevalence of airways obstruction in a general population: European Respiratory Society vs American Thoracic Society definition. Chest 2000, I I 5(5 Suppl 2):339S-345S.

20. Shahab L, Jarvis MJ, Britton J, West R: Prevalence, diagnosis and relation to tobacco dependence of chronic obstructive pulmonary disease in a nationally representative population sample. Thorax 2006, 61:1043-47.

21. Bakke PS, Baste V, Hanoa R, Gulsvik A: Prevalence of obstructive lung disease in a general population: relation to occupational title and exposure to some airborne agents. Thorax 1991, 46:863-70.

22. Mannino DM, Gagnon RC, Petty TL, Lydick E: Obstructive lung disease and low lung function in adults in the United States. Arch Intern Med 2000, 160:1683-89.

23. Jordan LM, Berra JCM, Inigo MC, Diez L, Garmendia Z: Enfermedad pulmonary obstructive cronica en la poblacion general. Estudio epidemiologico realizado em Guipuzcoa. Arch Bronchoneumol 1998, 34(I):23-27.

24. Murtagh E, Heaney L, Gingles J, Shepherd R, Kee F, Patterson C, MacMahon J: Prevalence of obstructive lung disease in a general population sample: The NICECOPD study. Eur J Epidemiol 2005, 20(5):443-453.

25. The Stationary Office Official documents [http:// www.archive2.official-documents.co.uk/document/deps/doh/ survey0l/rsac/rsac07.htm\#a26]

26. Sorlie PD, Kannel WB, O'Connor G: Mortality associated with respiratory function and symptoms in advanced age. The Framingham Study. Am Rev Respir Dis 1989, 140:379-84.

27. Knuiman MW, James AL, Divitini ML, Ryan G, Bartholomew HC, Musk AW: Lung function, respiratory symptoms, and mortality: results from the Busselton Health Study. Ann Epidemiol 1999, 9(5):297-306.

28. Devereux G: ABC of chronic obstructive pulmonary disease. Definition, epidemiology and risk factors. BMJ 2006, 332: 1 1 42-44.
29. Coultas DB, Mapel D, Gagnon R, Lydick E: The Health impact of undiagnosed airflow obstruction in a national sample of the United States adults. Am J Respir Crit Care Med 200I, I 64:372-77.

30. Godtfredsen NS, Vestbo J, Osler M, Prescott E: Risk of hospital admission for COPD following smoking cessation and reduction: A Danish population study. Thorax 2002, 57:967-72.

31. Anthonisen NR, Skeans MA, Wise RA, Manfreda J, Kanner RE, Connett JE, Lung Health Study Research Group: The effects of smoking cessation intervention on 14.5-year mortality. A randomized clinical trial. Ann Intern Med 2005, I 42:233-39.

32. Gorecka D, Bednarek M, Nowinski A, Puscinska E, Goljan-Geremek A, Zielinski J: Diagnosis of airflow limitation combined with smoking cessation advice increases stop-smoking rate. Chest 2003, I 23:1916-23.

33. Health and social care information centre: National Quality and Outcomes Framework Statistics for England 2004/05, Bulletin: 2005/04/ HSCIC Leeds, UK; 2005.

34. Eastern Region Health Observatory [http://www.erpho.org.uk/ ]
Publish with Biomed Central and every scientist can read your work free of charge

"BioMed Central will be the most significant development for disseminating the results of biomedical research in our lifetime. "

Sir Paul Nurse, Cancer Research UK

Your research papers will be:

- available free of charge to the entire biomedical community

- peer reviewed and published immediately upon acceptance

- cited in PubMed and archived on PubMed Central

- yours - you keep the copyright 